2014

\title{
Your Day in 'Wiki-Court': ADR, Fairness, and Justice in Wikipedia's Global Community
}

Sara Ross

Follow this and additional works at: http:// digitalcommons.osgoode.yorku.ca/olsrps

\section{Recommended Citation}

Ross, Sara, "Your Day in 'Wiki-Court': ADR, Fairness, and Justice in Wikipedia's Global Community" (2014). Osgoode Legal Studies Research Paper Series. 17.

http://digitalcommons.osgoode.yorku.ca/olsrps/17 


\title{
OSGOODE HALL LAW SCHOOL LEGAL STUDIES RESEARCH PAPER SERIES
}

Research Paper No. 56

Vol. 10/ Issue. 13/ (2014)

\section{Your Day in 'Wiki-Court': ADR, Fairness, and Justice in Wikipedia's Global Community}

Sara Ross

\section{Editors:}

Editor-in-Chief: Carys J. Craig (Associate Dean of Research \& Institutional Relations and Associate Professor, Osgoode Hall Law School, York University, Toronto)

Production Editor: James Singh (Osgoode Hall Law School, York University, Toronto)

\author{
This paper can be downloaded free of charge from: \\ http://ssrn.com/abstract=2495196
}

Further information and a collection of publications from the Osgoode Hall Law School Legal

Studies Research Paper Series can be found at:

http://papers.ssrn.com/sol3/JELJOUR_Results.cfm?form_name=journalbrowse\&journal_id=722488 
Osgoode Legal Studies Research Paper No. 56

Vol. 10/ Issue. 13/ (2014)

\title{
Your Day in 'Wiki-Court': ADR, Fairness, and Justice in Wikipedia's Global Community
}

\author{
Sara Ross
}

\begin{abstract}
:
Wikipedia has quickly become the largest volume of collected knowledge on the planet, but it is also one of the busiest centers for dispute resolution in the world. From small groups of individuals negotiating article changes on "talk pages", to the involvement of hundreds of people in the formation of the community consensuses needed to implement new policies, to the use of binding arbitration to create final conflict resolutions, the Wikipedia community has developed a complex network of norms and rules that funnel all disagreements and intractable differences through a series of progressively more involved dispute resolution processes. I provide an overview and analysis of the dispute resolution processes used by the community and will look to the successes and limitation of these processes. A number of flaws will be identified including the ability for vocal minorities to dominate the Wikipedia community consensus. A systemic bias will be identified in the behavioural landscape of the community and, finally, it will become apparent that there is room for growth in the website's inclusiveness, primarily through addressing the logistical realities of a potential user's access to the time, materials, and knowledge needed to become a contributing member of the Wikipedia community.
\end{abstract}

\section{Keywords:}

Wikipedia

\section{Author(s):}

Sara Ross

Osgoode Hall Law School

York University, Toronto

E: SaraRoss@osgoode.yorku.ca 


\section{YOUR DAY IN "WIKI-COURT": ADR, FAIRNESS, AND JUSTICE IN WIKIPEDIA'S GLOBAL COMMUNITY By: Sara Gwendolyn Ross*}

\section{INTRODUCTION}

Wikipedia has quickly become the largest volume of collected knowledge on the planet, but it is also one of the busiest centers for dispute resolution in the world. From small groups of individuals negotiating article changes on "talk pages", to the involvement of hundreds of people in the formation of the community consensuses needed to implement new policies, to the use of binding arbitration to create final conflict resolutions, the Wikipedia community has developed a complex network of norms and rules that funnel all disagreements and intractable differences through a series of progressively more involved dispute resolution processes.

The following will provide an overview and analysis of the dispute resolution processes used by the community and will look to the successes and limitation of these processes. A number of flaws will be identified including the ability for vocal minorities to dominate the Wikipedia community consensus. A systemic bias will be identified in the behavioural landscape of the community and, finally, it will become apparent that there is room for growth in the website's inclusiveness, primarily through addressing the logistical realities of a potential user's access to the time, materials, and knowledge needed to become a contributing member of the Wikipedia community.

In terms of scope, I confine myself to the English-language Wikipedia since other language versions of Wikipedia differ on numerous counts. ${ }^{1}$

\footnotetext{
${ }^{*}$ Sara Ross is a PhD candidate at Osgoode Hall Law School. She holds an LLM from the University of Ottawa Faculty of Law, both a BCL and LLB, with a major in Commercial Negotiation and Dispute Resolution, from the McGill University Faculty of Law, a BA Honors from McGill, and a BA from the University of Alberta. She is a former Editor-in-Chief of the McGill Law Journal and member of the Bar of Ontario.

${ }^{1}$ See Andrew Lih, The Wikipedia Revolution: How a Bunch of Nobodies Created the World's Greatest Encyclopedia (New York: Hyperion, 2009) ch 6.
} 


\section{A) THEORY AND METHODOLOGY}

I examine the Wikipedia community, and specifically the dispute resolution process, as a small social spaces within which the day-to-day realities of the Wikipedia community play out. ${ }^{2}$ While numerous studies have been conducted and published regarding different aspects of Wikipedia's governance structure, decision-making, and other discrete areas, ${ }^{3}$ my interest in the subject matter relates to its quasi-legal and dispute resolution mechanisms and group-interaction dynamics, especially within the context of legal pluralism and non-state law. ${ }^{4}$

My methodology investigates the narratives of the actors involved, case studies, as well as ethnography, in order to tease out systemic discrimination or injustice. With tools such as those provided by virtual ethnography, the Internet may be examined "as an object within people's lives and as a site [where] community-like formations [are] achieved and sustained in the ways in which it is used, interpreted and reinterpreted". 5

\section{BACKGROUND}

Founded in 2001, Wikipedia is a particularly interesting virtual community to study — as Stephen Colbert (a US political comedian) has quipped in the past: "The problem about Wikipedia is that it just works in reality, not in theory." ${ }^{6}$ Wikipedia is often the subject of discussions that attempt to define and categorize it — where it sits on the spectrum of bureaucracy to anarchy, or democracy to dictatorship. ${ }^{7}$ But as with any community, or site of governance or society, disputes arise, and mechanisms and norms develop in order to address these conflicts.

\footnotetext{
${ }^{2}$ For a discussion of the "small social space", see e.g. Sally Engle Merry, "Anthropology of International Law: (2006) 35 Annual Review of Anthropology 99 at 106.

${ }^{3}$ For a brief summary of the related literature, see e.g. Piotr Konieczny, "Adhocratic Governance in the Internet Age: A Case of Wikipedia" (2010) 7 Journal of Information Technology \& Politics 263 at 264.

${ }^{4}$ See also Brian Z Tamanaha, "Understanding Legal Pluralism: Past to Present, Local to Global" (2008) 30 Sydney L Rev 375.

${ }^{5}$ Christine Hine, Virtual Ethnography (London, UK: Sage Publications, 2000) at 64.

${ }^{6}$ Koneiczny, supra note 3 at 266-67.

${ }^{7}$ Ibid.
} 
It is also instructive to consider Wikipedia dispute resolution mechanisms as a case study in the larger context of Online Dispute Resolution that emerged "to fill a vacuum where law's authority was absent or inadequate" and the recurring chicken-or-the-egg question "where does law come from?"8 Does law emerge first with institutions implemented later for interpretive or enforcement purposes? Since Wikipedia is so near its genesis, it is possible to examine the way this self-managing community evolves in its treatment of disputes. Additionally, in terms of Online Dispute Resolution, where mediation and arbitration are thought of as alternatives to litigation in the "real" world, in cyberspace, these mechanisms cannot truly be identified as mere "alternatives" since no realistic recourse to litigation exists for disputes originating online. ${ }^{9}$

\section{A) THE ACTORS, HIERARCHIES, AND PRIVILEGES}

Theoretically, anyone with access to a standard web browser or mobile device with webaccess could become a Wikipedia editor who creates and edits articles. Almost all editors are volunteers, but within the ranks of those volunteers, each with equal access to edit and comment on the website's articles and policy documents, there are various privileges that can be bestowed in the form of user rights. Users rights allow access to different editing applications, like the ability to roll back multiple edits at once and create articles that do not need to be reviewed by another editor after posting, or reference databases that can make an editor's work more efficient.

Additionally, with experience, some editors can eventually become system operators, more commonly known as "Administrators", through an official community consensus process that determines if a volunteer is trustworthy, knowledgeable about the site's numerous policies,

\footnotetext{
${ }^{8}$ Ethan Katsh, "Online Dispute Resolution: Some Implications for the Emergence of Law in Cyberspace" (2007) 21 Int'l Rev L Comp \& Tech 97 at 98-99.

${ }^{9}$ Ibid at 101.
} 
and competent. ${ }^{10}$ Administrators have access to a particular administrative tool set-or, special "powers"- such as the ability to enable page protection (this blocks some types of users from editing a particular page), article deletion, and the ability to block users themselves from editing the site. ${ }^{11}$

There are also other tool sets or levels of site access that require similar electoral processes, such as those that accompany the Bureaucrat (who can appoint or remove Administrator status), Oversight (who can permanently delete material from the website), or Checkuser positions (who can trace the IP-addresses of anonymous user accounts if they are used inappropriately). The privileges of the Bureaucrat can be revoked by a small number of multilingual Stewards who are elected by the Wikipedia community and reconfirmed on a yearly basis. The powers of these Stewards can only be revoked by the Arbitration Committee or Wikipedia co-founder Jimmy Wales. ${ }^{12}$ The Arbitration Committee is also elected by the community, and even Wales' access level could be removed at any time by the community if it were so inclined.

\section{B) STRUCTURING FRAMEWORKS}

\section{i) Guidelines And Principles}

Within the policy and guideline documents that structure editor activity on Wikipedia, three guiding principles govern the content of Wikipedia's articles: (1) the content must demonstrate Verifiability ("V") in that it must be externally verifiable through the provision of links to third-party sources - the threshold for inclusion is verifiability, not truth; (2) the content

\footnotetext{
${ }^{10}$ Heather Hasan, Wikipedia, 3.5 Million Articles \& Counting: Using and Accessing the People's Encyclopedia (New York: Rosen Publishing Group, Inc, 2012) at 24.

${ }^{11}$ Sean Hansen, Nicholas Berente \& Kalle Lyytinen, "Wikipedia, Critical Social Theory" (2009) 25 The Information Society 38 at 42 .

${ }^{12}$ Hasan, supra note 10 at 24; Wikipedia Community, "Wikipedia:User_access_levels" (31 March 2014), online: Wikipedia <http://en.wikipedia.org>.
} 
must express a Neutral Point of View ("NPOV") such that there may not be any detectable bias on the part of the author; and (3) No Original Research ("NOR") is permitted in order to prevent the publication of a user's own particular views or findings. ${ }^{13}$

Wikipedia's guiding document of "fundamental principles" is called the "Five Pillars" policy. These five pillars are: that Wikipedia is to be written like an encyclopaedia and not any other form of reference work; NPOV; that the site is freely licensed and can be edited by anyone; that civility is important; and that Wikipedia itself does not have firm rules, which is often cited as a policy to "Ignore All Rules" by the editorial body. ${ }^{14}$ Other important principles that guide use are specifically related to dispute resolution between editors, communication, and discussion.

\section{WIKIPEDIA'S DISPUTE RESOLUTION PROCESSES}

\section{A) BACKGROUND}

The existence of conflicting opinions is central to the Wikipedia community. ${ }^{15}$ As such, it is no surprise that a relatively well-developed system for dispute resolution has become an important characteristic. While a dispute resolution mechanism was not always available, its genesis came early on in the history of Wikipedia. Early dialogue about implementing some sort of formal dispute resolution procedure can be traced to October of 2003 in the context of discussions related to "Wikiquette" principles for interacting with other editors. ${ }^{16}$

Regardless of protests against a highly developed judicial-like system, “[T]he law's shadow - actual and fanciful-loomed large over the early decisions about the kind of dispute

\footnotetext{
${ }^{13}$ Hansen, Berente \& Lyytinen, supra note 11 at 43; Mung Chiang, Networked Life: 20 Questions and Answers (Cambridge, Mass: Cambridge University Press, 2012) at 112; Wikipedia Community,

"Wikipedia:Verifiability_not_truth" (31 March 2014), online: Wikipedia <http://en.wikipedia.org>.

${ }^{14}$ Wikipedia Community, "Wikipedia:Five_pillars" (31 March 2014), online: Wikipedia <http://en.wikipedia.org>; Wikipedia Community, "Wikipedia:IAR" (31 March 2014), online: Wikipedia <http://en.wikipedia.org>.

${ }^{15}$ David A Hoffman \& Salik K Mehra, "Wikitruths Through Wikiorder" (2009) 59 Emory LJ 151 at 163.

${ }^{16}$ Ibid at 166.
} 
resolution system Wikipedians wanted to create". ${ }^{17}$ The original design of the dispute resolution process was based on the suggestion of a lawyer by the name of Alex T. Roshuk and inspired by a simplified form of the American Arbitration Association's arbitration programs. ${ }^{18}$ The very first arbitral decision was rendered on February $11,2004 .^{19}$

\section{B) DISPUTE RESOLUTION OVERVIEW}

Much of what happens on Wikipedia is not strictly held to written rules - the "law" of Wikipedia is informed through community norms and standards but structured through various policies and guidelines. ${ }^{20}$ Turning, however, to the Wikipedia dispute resolution process, it is characterized by informal processes as well as formal processes that ultimately deal with either content disputes or conduct disputes or, sometimes, disputes regarding policy. "Wikipedia is not about winning"-instead, the resolution of a dispute should clarify what should be done next as well as the lesson that can be learned from the dispute.

Civil discussions between disputing editors are encouraged and often required to move forward with formal processes as well as higher levels of informal processes. If a user is unable to prove they have made an effort to resolve a dispute with the opposing party, then they will not be allowed to use more formal methods of dispute resolution and are often reprimanded. Three main dispute resolution processes are available if the disputing parties cannot come to a consensus: (1) Request for Comment (“RfC”), (2) Formal Mediation, and (3) Arbitration.

\footnotetext{
${ }^{17}$ Ibid at 167.

${ }^{18}$ Ibid at 166 .

${ }^{19}$ Ibid at 169; Theresa Knott v Mr-Natural-Health (11 February 2004) online: Wikipedia <http://en.wikipedia.org/wiki/Wikipedia:Requests_for_arbitration/Theresa_knott_vs._Mr-Natural-Health> (Request for arbitration).

${ }^{20}$ An in-depth exploration of the many policies and regulations is beyond the present scope, but see (Phoebe Ayers, Charles Matthews \& Ben Yates, How Wikipedia Works and How You Can Be a Part of It (San Francisco: No Starch Press, 2008); Joseph Michael Reagle Jr, Good Faith Collaboration: The Culture of Wikipedia (Cambridge, Mass: MIT Press, 2010) at 51-53.
} 
Conflict management is thus based on a multi-tiered regulation and a "bottom-up" approach through the use of procedural rules. In terms of governance and regulation on the Internet, Wikipedia is the most comprehensive and formalized example of this genre of conflict management mechanism. ${ }^{21}$

The Request for Comment is an informal process while formal mediation and arbitration are both formal processes. Generally, mediation will deal with content-related disputes while arbitration will solely address conduct-related disputes as arbitration over content is not permitted. $^{22}$

\section{C) NEGOTIATION}

Negotiation is one of the most important skills and useful mechanisms within Wikipedia's dispute resolution processes since the site emphasizes discussion between editors with a view to consensus building. While real-world negotiation often views compromise as a viable outcome, within the Wikipedia context a compromise that is seen as "splitting the difference" is viewed as simplistic and unacceptable. ${ }^{23}$ The idea behind this view is that "splitting the difference" galvanizes both parties to take their positions to the extreme. Since one of the most valued principles of Wikipedia is that of neutrality, it is imperative that the compromise maintains the neutrality of content. As opposed to the simplistic compromise, the goal is to arrive at a principled agreement that takes into account Wikipedia's principles in terms of article topic, format, and editing as well as focuses on objective criteria such as verifiability, accuracy, reliability, and effective representation of the important points of view. ${ }^{24}$

\footnotetext{
${ }^{21}$ Nicholas Auray, "Online communities and governance mechanisms" in Eric Brousseau, Meryem Marzouki \& Cecile Meadel, eds, Governance, Regulation and Powers on the Internet (Cambridge, Mass: Cambridge University Press, 2012) 211 at 230.

${ }^{22}$ Wikipedia Community, "Wikipedia:Dispute_resolution” (31 March 2014), online: Wikipedia <http://en.wikipeida.org>.

${ }^{23}$ Wikipedia Community, "Wikipedia:Negotiation" (31 March 2014), online: Wikipedia <http://en.wikipedia.org>. ${ }^{24}$ Ibid.
} 


\section{D) THE INFORMAL DISPUTE RESOLUTION PROCESS}

By way of a brief introduction to the informal end of the dispute resolution process, talkpage or user-page discussion is the initial step, and only if that is unsuccessful will users proceed to the stage of "Request for Comment" ("RfC") or, alternatively, "Editor Assistance" from selfidentifying specialists in dealing with particular genres of disputes. At this stage, parties to a dispute may also request a "Third Opinion", which is a Wikipedia service volunteered by third-

party editors. ${ }^{25}$ Outside help with general advice in resolving a content dispute can also be sought through the Dispute Resolution Noticeboard. Other potentially useful and subject specific noticeboards include the Neutrality Noticeboard, the Reliable Source Noticeboard, the No Original Research Noticeboard, the Biographies of Living Persons Noticeboard, the Fringe Theories Noticeboard, the Conflict of Interest ("COI") Noticeboard, and the External Links Noticeboard.

\section{i) Venues For Debate}

In terms of the requisite discussion leading up to formal dispute resolution procedures, Wikipedia provides two main venues for debate: personal user talk-pages where somewhat private discussions can occur and the talk-page attached to each article, where editors involved on the same page can negotiate changes publicly. ${ }^{26}$ The history page of both the article and the talk-page, which show the differences between each edit that the article or its talk-page has ever had, is used as the basis for producing evidence of unconstructive editorial conduct should the

\footnotetext{
${ }^{25}$ Hoffman \& Mehra, supra note 15 at 172-73.

${ }^{26}$ Chiang, supra note 13 at $112-13$.
} 
need arise in the context of dispute resolution and arbitration. These history pages are the source of "diffs" or diff-links. ${ }^{27}$

\section{ii) Request for Comment ("RfC")}

This process occurs on the talk page adjacent to each article. The Request for Comment is an informal process where the Wikipedia community interacts in relation to a question or complaint related to the conduct of another editor, specific articles, content issues, or policies. ${ }^{28}$

The Request for Comment remains open until an administrator decides that enough time has passed and that all of the potential arguments have already been stated, such that it is unlikely that any other major arguments will be presented. Administrative closing opinions are given within the parameters of Wikipedia policy and generally the strongest argument shown during the discussion and prior to the close wins; it is unusual for an administrator to bring their own point-of-view or policy argument into the decision. A closing administrator must be "uninvolved", meaning that they cannot have been involved in the discussion at any point. When the administrator closes the Request for Comment, the result will be either that the discussion led to a "yes" or "no" consensus on the question at hand, or that there was "no consensus". If the dispute is related to content that is highly controversial, even where there is no consensus, the controversial content is generally removed.

\section{iii) Alternatives to the Request for Comment: Noticeboards}

\section{a) Administrator's Noticeboard/Incident}

While the other noticeboards mentioned above can be seen as an intermediary step before resorting to the Administrator's Noticeboard/Incidents ("ANI"), it is also possible to take a

\footnotetext{
27 "Diffs" or "diff-links" are a comparison that shows the difference between two versions of content and edits in an article, see Wikipedia Community, "Wikipedia:Diff" (31 March 2014), online: Wikipedia <http://en.wikipedia.org>. See further below for a discussion of "evidence".

${ }_{28}^{28}$ Ayers, Matthews \& Yates, supra note 20 at 397; Wikipedia Community, "Wikipedia:Request_for_comment" (31 March 2014), online: Wikipedia <http://en.wikipedia.org>.
} 
dispute directly to the ANI. The other noticeboards tend to be more specialized in particular policies for which editors can seek advice, and to be populated by a small core group of editors, rather than the wider range of individuals that join discussions at the ANI. While any administrator can warn or block an editor at the topic-specific noticeboards (or for infractions not brought up there at all), ANI is the only place where the permanent banning of an editor can occur. Many of the incidents brought before the ANI involve vandalism, serious paid advocacy, user conduct, or are related to the Neutral Point of View ("NPOV").

\section{E) FORMAL DISPUTE RESOLUTION PROCESSES}

Turning to Wikipedia's formal dispute resolution mechanisms, there are several aspects that are unique to the Wikipedia context. Again, the focus of the processes is mostly on conduct rather than content - the behaviour of the editors involved in the dispute is emphasized instead of the content of articles, even if the dispute originated with a dispute over content. ${ }^{29}$ But since communication and discussion are such important Wikipedian principles, most conflicts find their resolution through consensus building on talk-pages or noticeboards, prior to more formal processes. $^{30}$

\section{i) Formal Mediation}

Informal mediation by any Wikipedian may occur at any point in the attempt to resolve disputes. Formal mediation, however, forms a part of the formal dispute resolution processes available on Wikipedia and must be conducted by an appointed member of the Mediation Committee ("MedCom"). ${ }^{31}$ Any editor can become a member of the Mediation Committee if they are approved by community consensus. In order for mediation to begin, the majority of the

\footnotetext{
${ }^{29}$ Ayers, Matthews \& Yates, supra note 20 at 397.

${ }^{30}$ Ibid.

${ }^{31}$ Wikipedia Community, "Wikipedia:Mediation_Committee” (31 March 2014), online: Wikipedia $<$ http://en.wikipedia.org>.
} 
parties to the dispute must consent. Mediation can help to identify the root of the dispute. The intent is to stimulate formal discussions between the disputing parties in order to generate consensus that can be applied in practice. ${ }^{32}$

While formal mediation may precede arbitration, the formal mediation process is not a stepping stone to arbitration since the mediation process is privileged. As a result, mediation proceedings cannot be used in providing evidence during arbitral proceedings. ${ }^{33}$ In addition, the mediation proceedings must deal with content-related disputes and cannot solely treat editor conduct as disputes exclusively over the behaviour of editors are dealt with through the Arbitration Committee and arbitral proceedings.

In order for a request for mediation to be approved by the Mediation Committee, the parties must show that they have engaged in extensive dialogue in relation to the dispute. In addition, no related disputes or permutations of the dispute can be proceeding simultaneously elsewhere within Wikipedia forums. ${ }^{34}$

\section{ii) $\quad \underline{\text { Arbitration }}$}

Arbitration is the last resort and the involved parties must have proceeded through other dispute resolution processes before the Arbitration Committee accepts a request for arbitration. At this level, only conduct disputes may be heard. The Arbitration Committee (or "ArbCom") is Wikipedia's "highest court" and is comprised of twelve elected members who are voted in for three-year terms by the Wikipedia community. Arbitrators also have the power to examine the complaints that editors have against each other, ban editors from Wikipedia either in full or from certain topics, and are able to enact other restrictions. ${ }^{35}$ Contrary to the standard of anonymity

\footnotetext{
${ }^{32}$ Ayers, Matthews \& Yates, supra note 20 at 397.

33 "Wikipedia:Mediation_Committee", supra note 31.

34 Ibid.

${ }^{35}$ Koneiczy, supra note 3 at 269.
} 
amongst Wikipedia editors, members of the Arbitration Committee must disclose their realworld identity prior to appointment. This is also true of some other user-right levels.

In dealing with arbitral proceedings, the Arbitration Committee considers both sides of a dispute and, as opposed to the mediation process, will issue a "decision" rather than helping the parties come to their own resolution. The Arbitration Committee has the power to impose binding sanctions that are enforceable through administrative actions. ${ }^{36}$ Since arbitration is the last resort available in dispute resolution proceedings, once the dispute has arrived at this level, most of the involved parties will have played a part in conduct that is contrary to Wikipedia principles. As a result, sanctions often apply to most of the involved parties, whichever side they were on. While it is possible to appeal arbitration decisions to Jimmy Wales (the co-founder of Wikipedia), these appeals are not generally successful. ${ }^{37}$

Both private and public hearings may occur. Public hearings are the default form but summary proceedings may occur and a minority of cases may be heard in private. Appeals of bans that have been imposed on editors are usually heard by email. ${ }^{38}$

Arbitration proceedings may also provide a "workshop" mechanism for the parties to the dispute, interested members of the Wikipedia community, and members of the Arbitration Committee. The purpose of these workshops is to foster discussion, review, and comments surrounding the proposed elements of a final decision. ${ }^{39}$ The evidence presented in the context of the proceedings may also be viewed and commented upon at the bottom of the workshop page.

\section{iii) Evidence and Argumentation}

\footnotetext{
${ }^{36}$ Ayers, Matthews \& Yates, supra note 20 at 398; Wikipedia Community, "Wikipedia:Arbitration" (31 March 2014), online: Wikipedia <http://en.wikipedia.org>.

${ }^{37}$ Ayers, Matthews \& Yates, supra note 20 at 399.

${ }^{38}$ Wikipedia Community, "Wikipedia:Arbitration/Policy" (31 March 2014), online: Wikipedia $<$ http://en.wikipedia.org>.

${ }^{39}$ Wikipedia Community, "Wikipedia:Requests_for_arbitration/Template/Workshop" (31 March 2014), online: Wikipedia <http://en.wikipedia.org>.
} 
As with any formal dispute resolution process, evidence and argumentation play important roles. Arbitration in the Wikipedia context, however, has some interesting defining characteristics. Where, oftentimes, the process or procedure are key elements in legal and arbitral proceedings, Wikipedia's Arbitration Committee emphasizes the product, and the efficiency with which the product is achieved. ${ }^{40}$ Brevity is valued with the submission of evidence that is clear and concise. High-quality evidence that can speak for itself is preferred over numerous examples with extensive explanation. The context of the evidence is also important and again, civility should guide all argumentation and submission of evidence since it is one of the five pillars of Wikipedia. $^{41}$

Diffs constitute the primary source of available evidence to be presented. A diff basically demonstrates the conduct at issue through a comparison between two versions of a Wikipedia article. $^{42}$

\section{iv) Proposed decisions}

After receiving evidence, the arbitration decision is prepared over several weeks and contains four sections of proposals: General Principles, Findings of Fact, Remedies, and Enforcement Provisions.

A number of different bans related to particular matters may ultimately be enforced. Topic bans will limit an editor from editing in relation to a particular topic or point of view. The idea behind this kind of ban is that the editor still has the potential to remain or become a constructive member of the Wikipedia community in other topic areas. Site bans mean that the

\footnotetext{
${ }^{40}$ Wikipedia Community, "Wikipedia:Arbitration_guide”(31 March 2014), online: Wikipedia <http://en.wikipedia.org>.

41 “Wikipedia:Five_Pillars, 2014”, supra note 14; Ayers, Matthews \& Yates, supra note 20 at 364, 398.

42 "Wikipedia:Diff", supra note 27.
} 
editor will no longer be able to edit anything. This occurs when it is determined that the disruption the editor is causing is to the level that it is best to have them removed from the site.

An editor may become "unbanned" from the site by accepting a "standard offer". ${ }^{43}$ In order for this to occur, the editor must be able to demonstrate that they have respected the ban for six months and have not edited on Wikipedia. The editor seeking to be unbanned must also promise to avoid partaking in the kind of behaviour that initially led to the ban and must show an understanding of why the behaviour was disruptive as well as how the editor will edit differently in the future. The administrators will then consider the request for unbanning. In addition, there is a Ban Appeals Subcommittee to which a ban may be appealed. ${ }^{44}$ The return of an editor may be conditional upon certain limits or stipulations.

An editor may also be blocked from editing Wikipedia for a lesser period of time, which elapses automatically upon the completion of the sanction's period. Banned users are considered to be permanently blocked, and some indefinite blocks are considered to be de facto bans, although initiated by only a single individual rather than the community or Arbitration Committee. $^{45}$

\section{ANALYSIS OF THE DISPUTE RESOLUTION PROCEDURE}

\section{A) EDIT-WARRING AND THE "THREE-REVERT RULE"}

As noted previously, conflicts originate from either disputes over the content of an article or the conduct of an editor or, sometimes, a policy. An example of one of the most common bases for disputes is the "three-revert rule" (“3RR"), which is the bright line of edit-warring. ${ }^{46}$

\footnotetext{
${ }^{43}$ Wikipedia Community, "Wikipedia:Standard_offer” (31 March 2014), online: Wikipedia $<$ http://en.wikipedia.org>.

${ }^{44}$ Wikipedia Community, "Wikipedia:Arbitratiom_Committee/Ban_Appeals_Subcommittee” (31 March 2014), online: Wikipedia <http://en.wikipedia.org>.

${ }^{45}$ Wikipedia Community, "Wikipedia:Blocking_policy” (31 March 2014), online: Wikipedia $<$ http://en.wikipedia.org>.

${ }^{46}$ Wikipedia Community, "Wikipedia:Edit_warring” (31 March 2014), online: Wikipedia <http://en.wikipedia.org>.
} 
The three-revert rule disallows an editor from reverting the same edit or similar edits more than three times in a twenty-four period. ${ }^{47}$ Disputes arising from or involving three-revert rule violations demonstrate the mixture of content and conduct in a dispute. The dispute arises over the editing of content, but the ultimate infraction, and what might eventually be sanctioned, is the conduct of the editors that occurred in the context of the initially content-based dispute.

It is important to note the nuances of the three-revert rule when it is the basis of a dispute. If an editor takes another editor to task over the three-revert rule at a noticeboard and demonstrates that the other editor has been edit-warring, the conduct of the former will still be assessed to ensure that they have not also been retaliating in an edit-warring manner. It is hard to demonstrate another editor's involvement in edit-warring without being found to have partaken yourself. This also motivates editors to seek to resolve their disputes on their own in order to avoid involving other editors that may sanction both parties as a solution. Additionally, further recourse to dispute resolution mechanisms can only be accessed if the parties can tangibly demonstrate that they have attempted to discuss and resolve the conflict with each other over a substantial period of time. All this creates a situation where users are less likely to move forward through the more formal methods of dispute resolution, and instead attempt to resolve the dispute at a local level.

\section{B) FAIRNESS AND COMPETENCE IN DEALING WITH SENSITIVE MATTERS}

Disputes within the world of Wikipedia have an interesting dual dimension involving both the real world and the virtual world. Even where a dispute originates online, it will often have its roots in the real world. ${ }^{48}$ A dispute over sources used in an article, or a conflict of interest in its editing, is increased as the real world controversy over certain topics is heightened.

\footnotetext{
${ }^{47}$ Wikipedia Community, "Wikipedia:3RR" (31 March 2014), online: Wikipedia <http://en. wikipedia.org>.

48 Ayers, Matthews \& Yates, supra note 20 at 394.
} 
This becomes even more apparent when these real world controversies are over highly sensitive matters. For example, the recent tension over the sovereignty of Crimea is evidenced by tensions between Wikipedia contributors to the article on the region as well as vandalism. ${ }^{49}$

Related to sensitive matters and controversial political, social, or religious topics, one of Wikipedia's three core policies in place to ensure the neutrality and reliability of the contents of its articles is more likely to be the source of conflict than others. In comparison to Verifiability ("V") and No Original Research ("NOR"), the Neutral Point of View ("NPOV") policy is far

more difficult to determine. ${ }^{50}$ The subjectivity of the notion of neutrality leads not only to a regulatory challenge but also, in terms of conflict resolution, negotiation, consensus-building, and decision-making, it is more difficult for the community of Wikipedia editors to arrive at a rough consensus.

The intersect between real-world feelings about current events is one of the main triggers for problems that are not resolved at the local level as fundamental cultural or other differences between parties can obscure what point of view is truly neutral. In a sense, the dispute resolution process on Wikipedia works more efficiently when dealing with less heated content issues, and tends to tax the formal upper end of the system when dealing with the more significant social or political issues on its site.

\section{C) "ROUGH CONSENSUS" THROUGH "GOOD FAITH COLLABORATION"}

\footnotetext{
${ }^{49}$ Wikipedia Community, "Wikipedia:Crimea" (31 March 2014), online: Wikipedia <http://en.wikipedia.org>; Liz Fields, "Wikipedia is Battleground for Crimea War of Words", ABC News (19 March 2014) online: ABC News <http://abcnews.go.com>.

${ }^{50}$ Chiang, supra note 13 at 112-13.
} 
Most Wikipedian decisions follow the principles of "rough consensus". Consensus is preferred over voting. ${ }^{51}$ This approach looks to the strength of an argument as well as underlying policy rationales, if the latter applies. ${ }^{52}$

Polling is sometimes used within the process leading up to consensus. On its face, polling — selecting a position - may seem to be the same as voting. But the intent is to foster discussion within the community rather than putting an end to the discussion. Polling does not create consensus but instead illuminates the process en route to eventual consensus. ${ }^{53}$

That Wikipedia deals with disputes through consensus speaks to what may be perceived as injustice in certain cases, as this can allow a self-interested and vocal minority the ability to hijack group decisions. ${ }^{54}$ The use of consensus can skew towards preserving the status quo and conservative perspectives. Vocal minorities that are quick to forcefully express an opinion or position may benefit from support gained simply by being the first out of the gate to voice their views within a community where conformity and harmony are valued over effective and just representation of the interests of all community members. ${ }^{55}$

\section{i) Paid Editors}

The debates currently raging over paid editors and their presence within Wikipedia's volunteer basis are example of this. ${ }^{56}$ Paid editors are automatically considered to have a Conflict of Interest (“COI”), as past examples of paid editing work have shown preferential treatment to

\footnotetext{
${ }^{51}$ Reagle Jr, supra note 20 at 110.

52 Wikipedia Community, "Wikipedia:Rough_Consensus" (31 March 2014), online: Wikipedia <http://en.wikipedia.org>.

${ }^{53}$ Reagle Jr, supra note 20 at 110 )

${ }^{54}$ Wikipedia Community, "Wikipedia:Consensus" (31 March 2014), online: Wikipedia <http://en.wikipedia.org>.

${ }^{55}$ Reagle Jr, supra note 20 at 111.

${ }^{56}$ Simon Owens, “The Battle to Destroy Wikipedia's Biggest Sockpuppet Army", The Daily Dot (8 October 2013), online: The Daily Dot <http://www.dailydot.com>.
} 
the subjects being written about and a suppression of negative facts. ${ }^{57}$ While attempts to ban paid advocacy have occurred numerous times in the past, these attempts have each time been rejected by the community, which has built a consensus towards allowing paid editing to exist. ${ }^{58}$ However, a vocal minority vehemently against the practice continues to bring the issue up again in different forums with similar arguments, attempting to eventually force a change in the consensus.

\section{D) GENDER INEQUALITY}

While issues with small vocal minorities present a problem for Wikipedia dispute resolution, it is perhaps a small largely non-vocal minority that presents one of the greatest problems to Wikipedia. Since anonymity characterizes most of Wikipedia's contributors, it is impossible to be sure of the precise demographic makeup. However, general surveys of the matter specifically — and the reality of the Internet and computing context generally_indicate that there are more male contributors than female, with as high as $87 \%$ of users being male. ${ }^{59} \mathrm{~A}$ commonly cited reason for this asserts that Wikipedia culture is aggressive and intimidating. ${ }^{60}$ This is a particularly surprising assertion considering the emphasis Wikipedia places on civility - certainly civil language and aggressive and intimidating conduct are not mutually exclusive. The dispute resolution processes in this instance can be seen as developed in an exclusionary manner and not developed to be effective in a more multi-cultural or gender-neutral environment.

\footnotetext{
${ }^{57}$ Wikipedia Community, "Wikipedia:Conflict_of_interest”(31 March 2014), online: Wikipedia <http:en.wikipedia.org>; Wikipedia Community, "Wikipedia:Paid_editing" (31 March 2014), online: Wikipedia $<$ http:en.wikipedia.org >.

${ }^{58}$ Wikipedia Community, "Wikipedia:No_paid_advocacy"(31 March 2014), online: Wikipedia $<$ http:en.wikipedia.org>.

${ }^{59}$ Christopher Zara, “Wikipedia’s Gender Gap Persists: Why Don’t More Women Contribute to the Online Encyclopedia", International Business Times (19 August 2013), online: International Business Times <http://www.ibtimes.com>; Ayer, Matthews \& Yates, supra note 20 at 356.

${ }^{60}$ Ibid.
} 


\section{E) EXCLUSIONARY VERSUS INCLUSIONARY PRACTICE}

There are inevitable exclusionary aspects embodied in Wikipedia participationespecially considering the high level of active participation required in order to play a part in content or behaviour disputes. Time and access are key components of this exclusion. While Wikipedia policies are intended for the inclusion of all, this is not realistic. As Jorgensen notes, "Seen from a global perspective, the majority of contributions derive from developed countries, whereas contributions to Wikipedia from the developing part of the world are limited by lack of connectivity, many minority languages, and a small number of editors." ${ }^{.61}$

On the one hand, an example of inclusionary policies can be seen in Wikipedia's behavioural guideline "Please do not bite the newcomers", where hostile and impatient treatment of new members of the community is discouraged and the assumption of good faith and civility are emphasized. ${ }^{62}$ But, on the other hand, newcomers to the site are unlikely to have developed enough knowledge of Wikipedia policy to the level that would allow them to understand how to request the policy's enforcement.

The time required in order to be an active Wikipedian necessarily eliminates segments of society and individuals who - whether by choice or not—work the kinds of hours and jobs that do not permit the leisure time required. In addition to access to time, access to knowledge is perhaps what truly renders Wikipedia a "club of the privileged." ${ }^{23}$ As noted previously, even where a dispute occurs over conduct, the root cause is often based on a dispute over contentand a large portion of content-based disputes center around the proper sourcing of the content in question. An editor must not only have access to qualified knowledge, but must also know what

\footnotetext{
${ }^{61}$ Rikke Frank Jorgensen, Framing the Net: The Internet and Human Rights (Cheltenham: Edward Elgar Publishing, 2013) at 213.

${ }^{62}$ Wikipedia Community, "Wikipedia:Please_do_not_bite_the_newcomers" (31 March 2014), online: Wikipedia <http:en.wikipedia.org>.

${ }^{63}$ Jorgensen, supra note 61 at 213.
} 
kind of source adheres to Wikipedia policies on reliable sources with a view to verifiability. ${ }^{64}$ The dispute resolution process favours those in the "club of the privileged," producing a culture that can produce inherently biased decisions.

\section{CONCLUSION}

The small social space exemplified by the Wikipedia community of editors reveals the dispute resolution mechanisms that have been developed to mitigate editor content and conductbased disputes within a community where conflict plays a central role. Even where any hints of a legal framework were initially resisted, it is apparent that the need to develop mechanisms to resolve disputes was sorely needed in order to structure the community. In the online context, traditional forms of alternative dispute resolution become the only recourse rather than the alternative to litigation. Wikipedian dispute resolution also provides a glimpse into a system that values, above all, discussion and communication in the resolution of disputes. Especially striking about this focus on discussion is that it occurs entirely remotely and virtually. Fostering discussion between parties even when they are sequestered face-to-face in a room is no facile task, yet somehow this widely dispersed community has nonetheless created and abides by the norms of good communication and the goal of consensus-building.

However, the Wikipedian dispute resolution processes are no panacea of justice and fairness. This is at least in part due to the various levels of participation and investment in the project of building the largest volume of collected knowledge on the planet. The views of vocal minorities can dominate the environment of disputes due not only to varied levels of participation and, perhaps, apathy, but also due to the community's focus on harmony and conformity. Finally, as inclusionary as Wikipedia may profess to be, it is impossible to forget

\footnotetext{
${ }^{64}$ Wikipedia Community, "Wikipedia:Verifiability” (31 March 2014), online: Wikipedia <http://en.wikipedia.org>; Jorgenson, supra note 61 at 213.
} 
that the practice of Wikipedia involvement only permits participation by those with sufficient time and resources, and both logistical access as well as access to the knowledge needed for the Wikipedia community to allow newcomers to participate in a world governed by highly defined rules for source selection in order to maintain verifiability and neutrality. 